\title{
Effect of Heme Arginate Administration on Blood Pressure in Spontaneously Hypertensive Rats
}

Richard D. Levere, Pavel Martasek, Bruno Escalante, * Michal L. Schwartzman,* and Nader G. Abraham

Departments of Medicine and *Pharmacology, New York Medical College, Valhalla, New York 10595

\begin{abstract}
Cytochrome $\mathbf{P 4 5 0}$ content and activities are increased in the kidneys of spontaneously hypertensive rats (SHR) as compared with those of normotensive, Wistar-Kyoto (WKY), control rats during the period of rapid elevation of blood pressure. We studied the effect of heme arginate, a potent inducer of heme oxygenase (EC 1.14.99.3), on microsomal cytochrome P450 levels and activities and blood pressure in SHR at 7 wk of age. Administration of heme arginate $(15 \mathrm{mg} / \mathrm{kg}$ body weight for $4 \mathrm{~d}$ ) resulted in a marked decrease in blood pressure from $156.3 \pm 4.7$ to $129.8 \pm 4.5 \mathrm{~mm} \mathrm{Hg}(P<0.001)$, whereas blood pressure in SHR receiving the vehicle control was not affected. The blood pressure of age-matched WKY was not affected by heme arginate. Heme oxygenase activity increased in both hepatic and renal microsomes of SHR and WKY by two- to fourfold after treatment with heme arginate. Maximal increase of heme oxygenase mRNA occurred 5-7 $\mathrm{h}$ after the last injection of heme arginate and returned to control levels after $24 \mathrm{~h}$. The increase in heme oxygenase activity was associated with a parallel decrease in cytochrome $\mathbf{P 4 5 0}$ content and in the activity of cytochrome P450 $\omega / \omega-1$ arachidonate hydroxylases in kidneys of SHR. It is postulated that heme arginate treatment resulted in induction of heme oxygenase which consequently led to a diminution of cytochrome $\mathbf{P 4 5 0}$, especially the arachidonate $\omega / \omega-1$ hydroxylases leading to a marked decrease in 19-hydroxyeicosatetraenoic acid (HETE) and 20-HETE. The effect of heme arginate on blood pressure may be mediated via these biochemical events inasmuch as both 19-HETE and 20-HETE produced by the kidney may promote hypertension by causing vasoconstriction and sodium retention. (J. Clin. Invest. 1990. 86:213-219.) Key words: arachidonic acid • cytochrome P-450 - eicosanoids • heme oxygenase • spontaneously hypertensive rat/hypertension
\end{abstract}

\section{Introduction}

An acute attack of acute intermittent porphyria (AIP) ${ }^{1}$ is a life-threatening condition, often characterized by agonizing

Data in this report were presented in part at the National Meeting of the American Federation for Clinical Research, Washington, DC, May 1989. 1990.

Received for publication 15 June 1989 and in revised form 5 March

1. Abbreviations used in this paper: AA, arachidonic acid; AIP, acute intermittent porphyria; HETE, hydroxyeicosatetraenoic acid; SHR, spontaneous hypertensive rat(s); WKY, Wistar-Kyoto rat(s); ZnDPBG, zinc 2,4-deuteroporphyrin IX bis glycol.

J. Clin. Invest.

(c) The American Society for Clinical Investigation, Inc.

0021-9738/90/07/0213/07 \$2.00

Volume 86, July 1990, 213-219 abdominal pain and paresis and frequently accompanied by hypertension (1). The exact pathogenesis of hypertension in an acute porphyric attack is not well understood. Currently, heme arginate is used in Europe in the treatment of acute attacks of AIP so as to normalize the levels of "free" heme and thereby decrease the induced levels of $\delta$-aminolevulinic acid synthetase, an enzyme under negative feedback control by unbound or "free" heme (2-6). Kordac and co-workers (7) observed rapid normalization of hypertension after administration of heme arginate to patients with attacks of AIP. This observation prompted us to study the effect of this compound on blood pressure in spontaneously hypertensive rats (SHR), the animal model of human essential hypertension (8). In this model, blood pressure increases most rapidly from 100 to $170 \mathrm{~mm} \mathrm{Hg}$ between 5 and $13 \mathrm{wk}$ of age, whereas in the age-matched normotensive rat systolic blood pressure rarely exceeds $130 \mathrm{~mm}$ $\mathrm{Hg}$. Elevation of blood pressure in the SHR can be partially suppressed by a renal transplant from a normotensive donor, suggesting that abnormalities in kidney function are responsible, in part, for the elevation of blood pressure in SHR (9). These abnormalities consist of reduced excretion of sodium and water, decreased renal blood flow, and decreased glomerular filtration rate. The resetting of renal function appears to occur early in the SHR and may be necessary for the development of hypertension (10). For example, fractional sodium and water excretion were significantly less in the SHR when compared with age-matched Wistar-Kyoto rats (WKY), a difference which disappeared by 8 wk of age (11).

An increase in hepatic and renal cytochrome P450 content and its related drug metabolizing enzyme systems has been demonstrated in SHR $(12,13)$. More recently, we (13) have demonstrated that abnormalities of renal function in young SHR may be a functional expression of an alteration in renal cytochrome P450-dependent metabolism of arachidonic acid (AA). Cytochrome P450 levels are regulated by the availability of cellular heme which in turn is controlled by the levels of heme oxygenase which is the controlling enzyme in the metabolism of heme to bilirubin. Induction of heme oxygenase by heavy metals such as $\mathrm{SnCl}_{2}$ results in a depletion of renal cytochrome P450 $(14,15)$ and causes a selective depletion of renal cytochrome $\mathbf{P 4 5 0}$ and a concomitant marked decrease in blood pressure and an increase in sodium excretion in 7-wkold SHR (16). Furthermore, it has recently been demonstrated $(17,18)$ that AA metabolites of cytochrome P450 $\omega / \omega-1$ hydroxylases, 19(S)-hydroxyeicosatetraenoic acid (HETE) and 20-HETE, are biologically active. 19(S)-HETE is a potent renal $\mathrm{Na}^{+}-\mathrm{K}^{+}$-ATPase stimulator and 20 -HETE is a vasoconstrictor. Thus both metabolites may promote renal vasoconstriction and sodium retention, biological activities that promote hypertension.

Heme arginate is a pharmacological agent with the ability to induce heme oxygenase (2). It is a stable compound bonding one molecule of hemin to three molecules of arginine and 
forming a high spin-type compound. The half-life of heme arginate in humans is $10.8 \pm 0.6 \mathrm{~h}$ with a volume distribution of 3.37 \pm 0.34 liter.

In this study, we examined the effect of repeated administration of heme arginate in young SHR, and correlated the effect on blood pressure with changes in renal heme oxygenase, cytochrome P450 content, and cytochrome P450-related AA metabolism. Further, the mechanism of heme arginate on induction of heme oxygenase was also examined.

\section{Methods}

Animals. 5-wk-old male SHR and normotensive WKY were purchased from Charles River Breeding Laboratories, Inc. (Wilmington, MA) and fed and housed under identical conditions. Both SHR and WKY weighed the same at the beginning of the study, $116.3 \pm 12.5$ and $120.6 \pm 12.0 \mathrm{~g}$, respectively. 45-d-old SHR and WKY were injected with either hemin, L-arginine, or heme arginate, 9,15 , or $30 \mathrm{mg} / \mathrm{kg}$ body weight, intraperitoneally, in a final volume of $1.0 \mathrm{ml}$ of saline for $4 \mathrm{~d}$ consecutively (dilution was made just before injection). The heme arginate was obtained from Normosang, Leiras-Medica, Turku, Finland. Each ampule contained $25 \mathrm{mg}$ of hemin bound to $26.7 \mathrm{mg}$ of L-arginine in $1 \mathrm{ml}$ of saline. Rats treated with $\mathrm{Zn}$-2,4-deuteroporphyrin IX bis glycol (ZnDPBG; Porphyrin Products, Logan, UT) were injected subcutaneously with $0.2 \mathrm{ml}$ of a freshly prepared $\mathrm{ZnDPBG}$ solution. The control SHR and WKY were injected with saline. Blood pressure from the tail was measured without anesthesia using a plethysmograph before and $23 \mathrm{~h}$ after the last injection.

Control and treated animals were killed in pairs 5, 7, and $24 \mathrm{~h}$ after the last heme arginate administration. One kidney from each rat and parts of liver were immediately frozen in liquid nitrogen for RNA extraction. The remaining control and treated animals were killed $24 \mathrm{~h}$ after heme arginate treatment. Livers and kidney were perfused with cold saline. Groups of control and treated animals were kept for study of the long-term effect on blood pressure after heme arginate treatment at age 45-48 d; blood pressure was measured once a week from 7 to 13 wk of age.

Cytochrome $P 450$ content. Livers were immediately perfused with cold saline, sliced, and homogenized $(4 \mathrm{ml} / \mathrm{g}$ wet weight) in $10 \mathrm{mM}$ Tris buffer, $\mathrm{pH} 7.5$, containing $0.25 \mathrm{M}$ sucrose. The tissue homogenates were centrifuged at $27,000 \mathrm{~g}$ for $20 \mathrm{~min}$ at $4^{\circ} \mathrm{C}$. The supernatant was centrifuged at $105,000 \mathrm{~g}$ for $1 \mathrm{~h}$ at $4^{\circ} \mathrm{C}$, and the resulting microsomal pellet was resuspended in $0.1 \mathrm{M}$ potassium phosphate buffer, pH 7.6. Protein concentration was determined by the method of Lowry et al. (19) with bovine serum albumin (fraction V) as a standard. Cytochrome P450 content was measured from the reduced carbon monoxide difference spectrum using sodium dithionite as the reducing agent. The absorbance difference between 450 and $490 \mathrm{~nm}$ was monitored and cytochrome P450 content calculated using a molar extinction coefficient of $91 \mathrm{mM}^{-1} \mathrm{~cm}^{-1}(20)$.

Cytochrome P450 AA metabolism. AA metabolism was measured as described previously (13). Briefly, microsomal suspensions $(0.3 \mathrm{mg}$ protein) were preincubated with indomethacin $(10 \mu \mathrm{M})$ for $10 \mathrm{~min}$ and further incubated with $7 \mu \mathrm{M}\left[1-{ }^{14} \mathrm{C}\right] \mathrm{AA}$ and NADPH $(1 \mathrm{mM})$, for 30 $\min$ at $37^{\circ} \mathrm{C}$. The reaction was terminated by acidification with citric acid to $\mathrm{pH}$ 4.5-5.0 and extracted twice with 2 vol of ethyl acetate. The final extracts were evaporated and AA metabolites were separated by high-pressure liquid chromatography (HPLC). Reverse-phase HPLC was performed on a $\mathrm{C}_{18}$ Bondapack (Waters Associates, Milford, MA) with a linear gradient from acetonitrile/water/acetic acid (500:500:1, by volume) to acetonitrile/acetic acid $(1,000: 1, \mathrm{vol} / \mathrm{vol})$ at a flow rate of $1 \mathrm{ml} / \mathrm{min}$ for $\mathbf{4 0} \mathrm{min}$. Radioactivity was monitored by a flow detector (Radiomatic Instruments \& Chemical Co. Inc., Tampa, FL).

Measurement of heme oxygenase activity. Heme oxygenase activity was assayed by the method of Tenhunen et al. (21) as modified by Abraham et al. (22) in which the product of heme oxygenase, bilirubin, was extracted with chloroform and determined in a spectrophotometer (model DW-2C, Aminco, Urbana, IL), using the difference in absorption from 460 to $530 \mathrm{~nm}$ and standard curve obtained with various dilutions of bilirubin.

Heme oxygenase mRNA levels in rat liver and kidney. The levels of heme oxygenase mRNA in rat liver and kidney were determined by Northern blot analysis of total RNA using cDNA for rat heme oxygenase. The probe used in this study was the 883 base-pair EcoR1Hind III fragment of pRHO1, a plasmid containing full-length cDNA for rat spleen heme oxygenase $(23,24)$. This fragment contains the structural gene for all but the first 29 amino acid residues of the enzyme and has been shown to cross-react with heme oxygenase mRNA in rat liver and glioma cells (25). The DNA probe was labeled according to the primer extension technique of Feinberg and Vogelstein (26). RNA was extracted from rat liver and kidney using the guanidinium isothiocyanate/cesium chloride method. $8 \mu \mathrm{g}$ of total RNA from kidney and liver was electrophoresed on gels containing $1 \%$ agarose and 1 $M$ formaldehyde, transferred to nitrocellulose, and hybridized with the ${ }^{32} \mathrm{P}$-labeled probe. The relative amounts of heme oxygenase mRNA present in the kidneys and livers were obtained from the counting of excised filters corresponding to the positive signals of $\sim 18 \mathrm{~S}$. The size markers were rate and bacterial ribosomal RNA. Autoradiography was performed for varying lengths of time at $-80^{\circ} \mathrm{C}$ using XAR-5 film (Eastman Kodak Co., Rochester, NY) with Lighting-Plus intensifying screens (DuPont Co., Wilmington, DE).

Statistical analysis. Statistical significance was determined by analysis of variance (ANOVA). The null hypothesis was rejected if the $P$ value was $<0.05$, as calculated, using Newman-Keuls test for multiple group comparisons. For comparisons of two groups an unpaired $t$ test was used.

\section{Results}

Effect of heme arginate on systolic blood pressure. In preliminary experiments we determined the dose-response relationship of hemin, L-arginine, and heme arginate with respect to blood pressure. Heme arginate, as well as hemin and L-arginine, were given for $4 \mathrm{~d}$ consecutively as is done with heme arginate in acute hepatic porphyric patients (3). As seen in Fig. 1 , at the three doses used all substances significantly reduced blood pressure of 7-wk-old SHR. Although the effect of both $\mathrm{L}$-arginine and hemin seems to plateau at $15 \mathrm{mg} / \mathrm{kg}$, the synergism of hemin and L-arginine in the form of heme arginate was evident at both 15 and $30 \mathrm{mg} / \mathrm{kg}$ body weight/day (Fig. 1). We therefore performed all the experiments described in these studies on rats treated with heme arginate or related compounds at a dose of $15 \mathrm{mg} / \mathrm{kg}$ body weight for $4 \mathrm{~d}$ consecutively. Administration of heme arginate, $15 \mathrm{mg} / \mathrm{kg}$ body weight/d for $4 \mathrm{~d}$, resulted in a marked decrease in blood pressure in 7-wk-old SHR $(156.3 \pm 4.7$ vs. $129.8 \pm 4.5 \mathrm{~mm} \mathrm{Hg}$, for control and treated rats, $n=8, P<0.001$ ), whereas no significant changes in blood pressure were monitored in agematched WKY $(119.5 \pm 3.3$ vs. $121.0 \pm 2.1 \mathrm{~mm} \mathrm{Hg}$ for control and treated rats, $n=8)$. The effect of heme arginate could be detected after the first day of its administration. The maximal effect was achieved by the fourth day of treatment, but blood pressure started to increase after cessation of heme arginate administration (Fig. 2). Furthermore, the heme arginate effect on blood pressure was also evident in 22-wk-old SHR. Administration of heme arginate at 15 and $30 \mathrm{mg} / \mathrm{kg}$ body weight for $4 \mathrm{~d}$ decreased blood pressure by $7 \mathrm{~mm} \mathrm{Hg}$ (from 193.3 \pm 2.1 to $187.5 \pm 1.3 \mathrm{~mm} \mathrm{Hg}, n=4, P<0.005$ ) and $12 \mathrm{~mm} \mathrm{Hg}$ (from $198.1 \pm 4.8$ to $185.7 \pm 4.2 \mathrm{~mm} \mathrm{Hg}, n=3, P<0.05$ ), respectively. Although the heme arginate effect on blood pressure in 


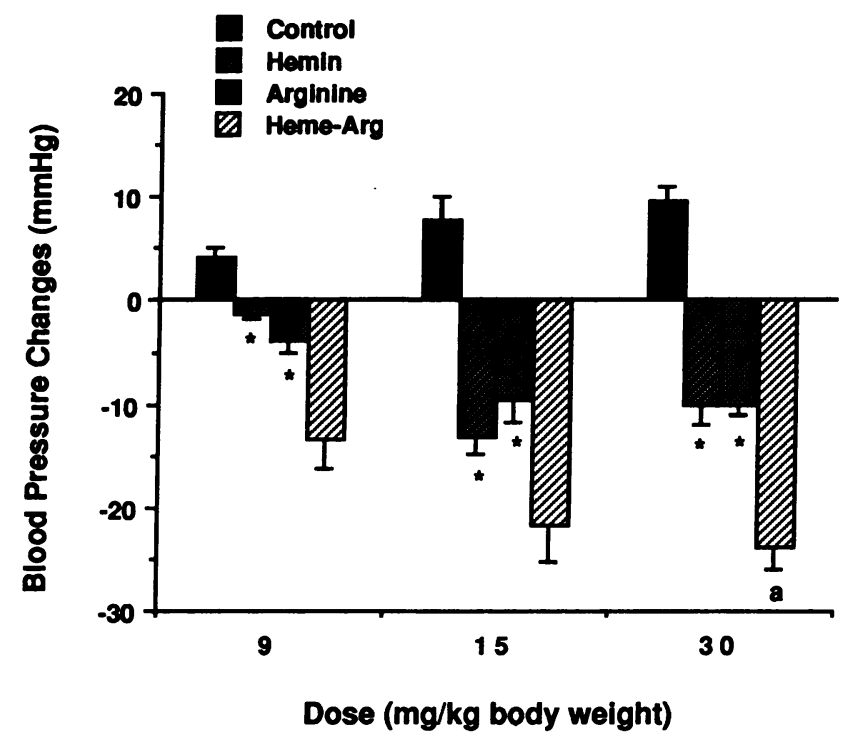

Figure 1. Changes in blood pressure after hemin, L-arginine, and heme arginate treatment of 7-wk-old SHR. 45-d-old SHR were treated with hemin, L-arginine, and heme arginate. Hemin and heme arginate were given at 9,15 , and $30 \mathrm{mg} / \mathrm{kg}$ body weight per $\mathrm{d}$ for $4 \mathrm{~d}$. Since $25 \mathrm{mg}$ of hemin was bound to $26.7 \mathrm{mg}$ of L-arginine in the heme arginate stock solution, the doses of $\mathrm{L}$-arginine administered were slightly higher, $9.6,16$, and $32 \mathrm{mg} / \mathrm{kg}$ body weight per d, to reflect its content in the heme arginate molecule. Control SHR were injected with saline. Systolic blood pressure was measured by tail cuff plethysmography $23 \mathrm{~h}$ after the last injection. Results represent the difference in blood pressure before and after $4 \mathrm{~d}$ of treatment and are the mean \pm SE; $n=4$ for 9 and $15 \mathrm{mg} / \mathrm{kg}$ groups and $n=5$ for 15 $\mathrm{mg} / \mathrm{kg}$ group. In all doses studied, the control values were significantly different from hemin, L-arginine, and heme arginate-treated, $P<0.05$; significance from heme arginate-treated group, ${ }^{*} P<0.01$; significance from $9 \mathrm{mg} / \mathrm{kg}$ body weight, ${ }^{a} P<0.05$.

older SHR was much lower than in younger SHR, i.e., a decrease of blood pressure of 7 vs. $26 \mathrm{~mm} \mathrm{Hg}$ for 20- and 7-wkold SHR, respectively, it was significantly different from controls.

We further examined whether the effect is due to hemin or to the arginine component of heme arginate. In separate experiments, we treated 7-wk-old SHR with heme arginate, hemin alone, and L-arginine alone at the same dose $(15 \mathrm{mg} / \mathrm{kg}$ body weight). As seen in Table I, both hemin and L-arginine significantly reduced blood pressure in 7-wk-old SHR by 14.3 and $9.7 \mathrm{~mm} \mathrm{Hg}$, respectively. At the same period blood pressure in control SHR increased by $7.7 \mathrm{~mm} \mathrm{Hg}$. However, the effect of heme arginate on blood pressure had a much greater decrease of $21.8 \mathrm{~mm} \mathrm{Hg}$, which is the sum of the hemin and arginine effects (Table I). Interestingly, when 7-wk-old SHR were treated with heme arginate and an inhibitor of heme oxygenase, ZnDPBG (27), blood pressure decreased by only 14 $\mathrm{mm} \mathrm{Hg}$ and was significantly higher than that of the heme arginate-treated SHR. The heme oxygenase inhibitor alone did not have any effect on blood pressure (Table I).

Effect of heme arginate on heme oxygenase activity. The last observation raised the possibility that the effect of heme arginate is in part associated with heme oxygenase activity as recently demonstrated for $\mathrm{SnCl}_{2}$ (16). We therefore measured the effect of heme arginate on the level and activity of heme

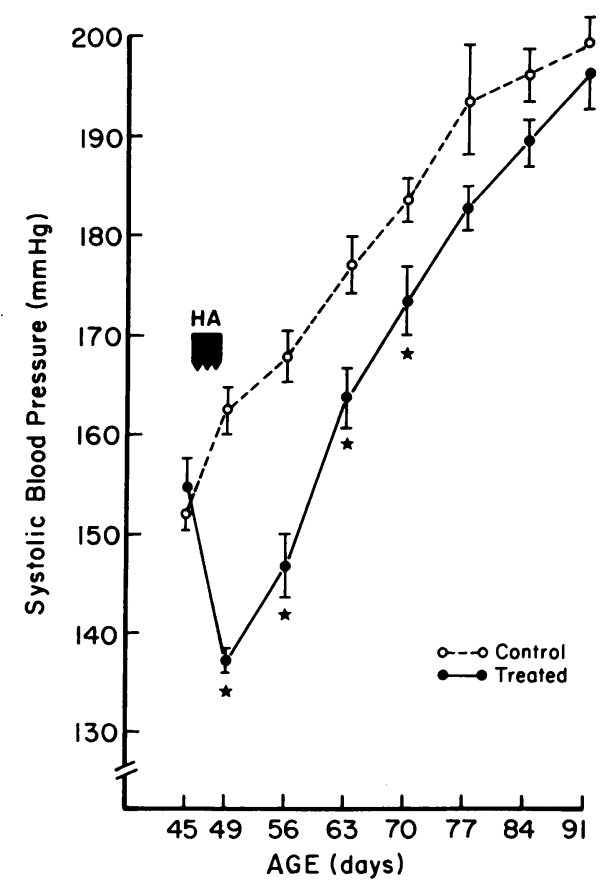

Figure 2. Long-term effect of heme arginate on systolic blood pressure. 45 -d-old SHR were injected with heme arginate $(15 \mathrm{mg} / \mathrm{kg})$ for $4 \mathrm{~d}$ consecutively. Control SHR were injected with the vehicle. Systolic blood pressure was measured by tail cuff plethysmography before and $24 \mathrm{~h}$ after the last injection and then every week as indicated. Results are the means $\pm \mathrm{SD}, n=3$ in each group; significance from control group, ${ }^{*} P<0.01$.

oxygenase. As seen in Fig. 3, heme oxygenase activity in both liver and kidney of 7-wk-old SHR was induced by three- to fivefold within $5 \mathrm{~h}$ after heme arginate administration. Hepatic heme oxygenase activity slightly declined within $24 \mathrm{~h}$ after

Table I. Systolic Blood Pressure in 7-wk-old SHR

\begin{tabular}{lcc}
\hline & \multicolumn{2}{c}{ Systolic blood pressure } \\
\cline { 2 - 3 } & $\begin{array}{c}\text { Before } \\
\text { treatment }\end{array}$ & $\begin{array}{c}\text { After } \\
\text { treatment }\end{array}$ \\
\hline & \multicolumn{3}{c}{$m m ~ H g$} \\
Control & $158.4 \pm 4.1$ & $166.0 \pm 2.7$ \\
Heme arginate $(15 \mathrm{mg} / \mathrm{kg})$ & $154.3 \pm 1.9$ & $132.5 \pm 7.3^{*}$ \\
Hemin $(15 \mathrm{mg} / \mathrm{kg})$ & $156.5 \pm 3.3$ & $142.2 \pm 2.4^{* \pm}$ \\
L-arginine $(16 \mathrm{mg} / \mathrm{kg})$ & $154.1 \pm 4.5$ & $144.4 \pm 3.0^{* \ddagger}$ \\
Heme arginate $(15 \mathrm{mg} / \mathrm{kg})$ & & \\
$\quad+$ ZnDPBG $(7 \mathrm{mg} / \mathrm{kg})$ & $160.4 \pm 3.8$ & $146.5 \pm 2.6^{* \ddagger}$ \\
ZnDPBG $(7 \mathrm{mg} / \mathrm{kg})$ & $154.0 \pm 4.0$ & $169.1 \pm 2.5^{\S}$ \\
\hline
\end{tabular}

Systolic blood pressure was measured by tail cuff plethysmograph before and $23 \mathrm{~h}$ after the last injection as described in Methods. ZnDPBG was injected subcutaneously $2 \mathrm{~h}$ before each heme arginate administration. $15 \mathrm{mg}$ of heme arginate is equivalent to $15 \mathrm{mg}$ of hemin bound to $16 \mathrm{mg}$ of $\mathrm{L}$-arginine. Results are the means $\pm \mathrm{SD}, n$ $=5$ in each group; ${ }^{*} P<0.01$, significance from control SHR after 4 $\mathrm{d}$ of treatment with the vehicle $(166.0 \pm 2.7 \mathrm{~mm} \mathrm{Hg}) ;{ }^{\ddagger} P<0.01$, significance from heme arginate-treated group; ${ }^{\S} P<0.01$, significance from group treated simultaneously with heme arginate and $\mathrm{ZnDPBG}$. 


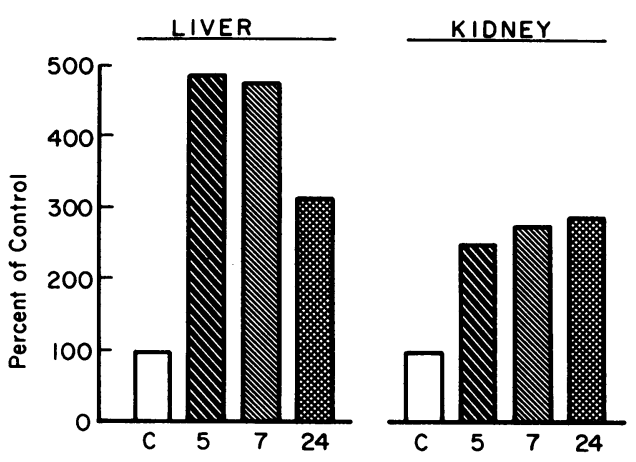

Figure 3. Effect of heme arginate on hepatic and renal heme oxygenase activities in SHR. 45-d-old SHR were injected with heme arginate $(15 \mathrm{mg} / \mathrm{kg}$ body weight) for $4 \mathrm{~d}$ consecutively. The animals were killed 5, 7, and $24 \mathrm{~h}$ after the last injection of heme arginate. Liver and kidney microsomes were prepared and heme oxygenase activities determined as described in Methods. Each column represents the mean of two determinations done in duplicate. Control hepatic heme oxygenase activity is $0.891 \mathrm{nmol}$ bilirubin/mg per $\mathrm{h}$; and for renal heme oxygenase is $0.446 \mathrm{nmol} / \mathrm{mg}$ per $\mathrm{h} ; C$, control; numbers represent hours after last heme arginate injection.

treatment, whereas renal activity remained induced. The specificity of heme arginate as an inducer of heme oxygenase was further demonstrated by Northern blot analysis using rat cDNA heme oxygenase. As seen in Fig. 4, Northern blot analysis of heme oxygenase clearly demonstrated that heme oxygenase mRNA increased drastically as a result of administration of heme arginate. The maximum induction of heme oxygenase mRNA was noticed between 5 and $7 \mathrm{~h}$ after the last injection of heme arginate in both kidney and liver (Fig. 4). In both kidney and liver the level of heme oxygenase mRNA returned to control levels $24 \mathrm{hrs}$ after the last injection of heme arginate (Fig. 4, lane $C$ ). A similar pattern of induction of heme oxygenase mRNA was also seen in the age-matched WKY pretreated with heme arginate (data not shown).

Hemin, at a dose of $15 \mathrm{mg} / \mathrm{kg}$ also induced renal and hepatic heme oxygenase activity to the same extent as heme
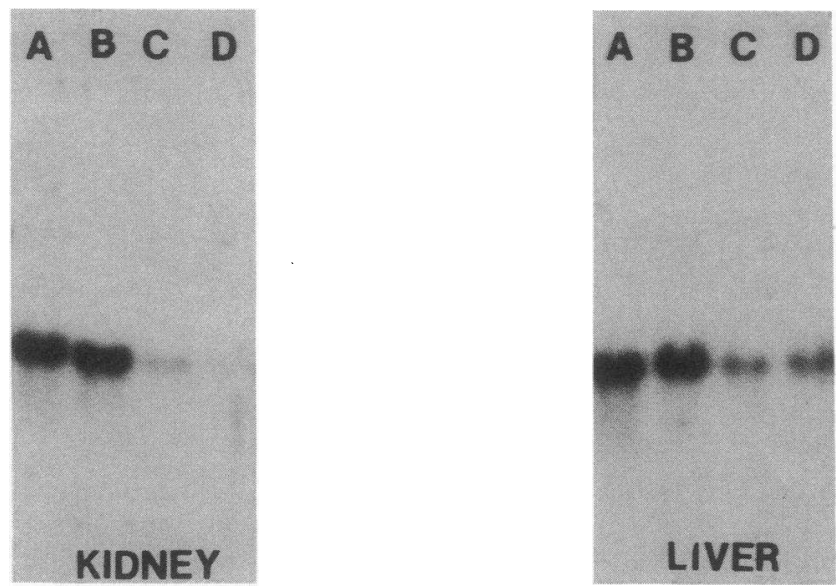

Figure 4. Northern hybridization analysis of kidney and liver in SHR. Hybridization of heme oxygenase probe to total RNA $(8 \mu \mathrm{g})$ from kidney and liver before and after administration of heme arginate ( $15 \mathrm{mg} / \mathrm{kg}$ body weight). Lane $A, 5 \mathrm{~h}$; lane $B, 7 \mathrm{~h}$; lane $C, 24 \mathrm{~h}$ after heme arginate injection; and lane $D$, control. arginate (Figs. 5 and 6), however, its lowering effect on blood pressure (Table I) was less than that of heme arginate when given at the same dose. L-arginine, at a dose of $16 \mathrm{mg} / \mathrm{kg}$, did not induce heme oxygenase (data not shown), suggesting that unlike hemin and heme arginate, its blood pressure lowering effect is not associated with an induction of heme oxygenase.

Effect of heme arginate on cytochrome P450-related AA metabolism. The above observations suggest that the hemin component of heme arginate affects blood pressure probably by inducing heme oxygenase. Similar results were previously demonstrated for another inducer of heme oxygenase, $\mathrm{SnCl}_{2}$, where subsequent reduction in cytochrome P450-dependent arachidonate metabolites (20- and 19-HETEs) were thought to account for the decrease in blood pressure (16). We, therefore, studied the effect of heme arginate on cytochrome P450 levels and its dependent AA oxidations. The basal level of cytochrome P450 in both kidney and liver of 7-wk-old SHR is significantly higher than that in age-matched WKY (references 13 and 14 and Fig. 7). Interestingly, the basal level of hepatic heme oxygenase in WKY is $50 \%$ higher than that in SHR (Fig. 7). When SHR were treated with heme arginate or hemin alone at a dose of $15 \mathrm{mg} / \mathrm{kg}$, a decrease in hepatic and renal cytochrome P450 level was observed (Figs. 5 and 6). The reduction in renal cytochrome $\mathrm{P} 450$ was associated with a reduction in $\omega / \omega-1$ hydroxylation of AA. As seen in Fig. 8, AA is oxygenated by renal cortical cytochrome P450 to $\omega / \omega-1$ hydroxylated products (19- and 20-HETE) and to epoxygenase products $(11,12$ epoxyeicosatrienoic acid [EET] and its hydrolytic metabolite 11,12 dihydroxyeicosatrienoic acid [DHT]). In the SHR, production of 19- and 20-HETE is markedly increased during the development of hypertension (13). The

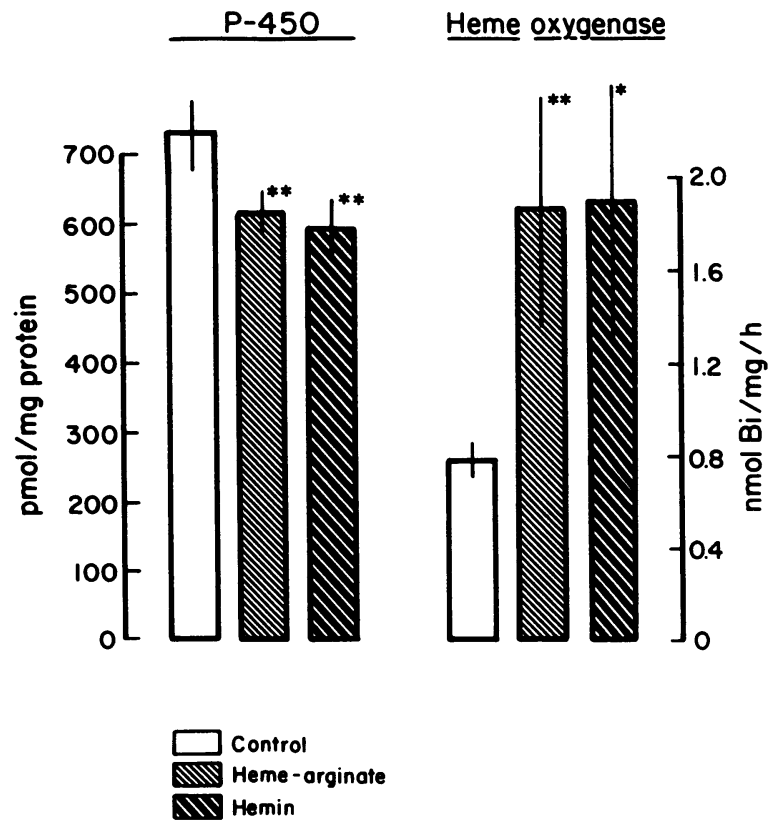

Figure 5. Effect of hemin and heme arginate on hepatic heme oxygenase activity and cytochrome P450 content in 7-wk-old SHR. 45-d-old SHR were treated with hemin $(15 \mathrm{mg} / \mathrm{kg}$ body weight $)$ or heme arginate ( $15 \mathrm{mg} / \mathrm{kg}$ body weight) for $4 \mathrm{~d}$ consecutively. Microsomal cytochrome P450 content and heme oxygenase activity were measured as described in Methods. Results are means $\pm \mathrm{SD}, n=5$ for each group; significance from control group, ${ }^{*} P<0.05,{ }^{* *} P<0.01$. 

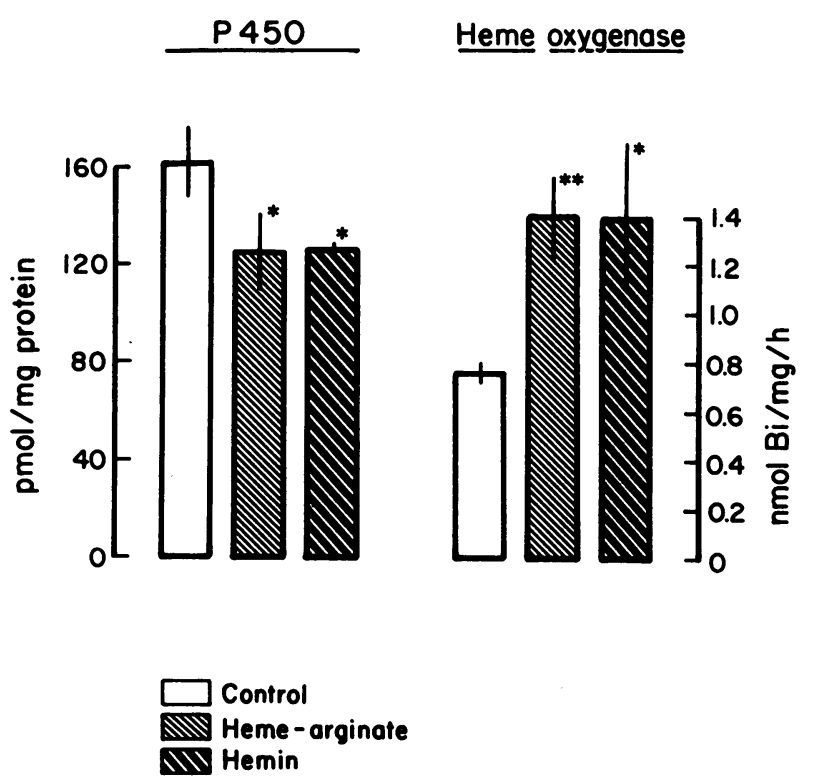

Figure 6. Effect of hemin and heme arginate on renal heme oxygenase activity and cytochrome P450 content in 7-wk-old SHR. 45-dold SHR were treated with either hemin ( $15 \mathrm{mg} / \mathrm{kg}$ body weight) or heme arginate $(15 \mathrm{mg} / \mathrm{kg}$ body weight) for $4 \mathrm{~d}$ consecutively. Renal cortical microsomes were prepared and heme oxygenase activity and cytochrome P450 content measured as described in Methods. Results are means $\pm \mathrm{SD}, n=3$ in each group; significance from control, ${ }^{*} P<0.05$.

effects of heme arginate and its components at doses of 15 $\mathrm{mg} / \mathrm{kg}$ body weight on cytochrome P450-related arachidonate metabolism is summarized in Table II. It is clear that the main effect of either hemin or heme arginate, inducers of heme oxygenase, is a reduction in the formation of 19- and 20-

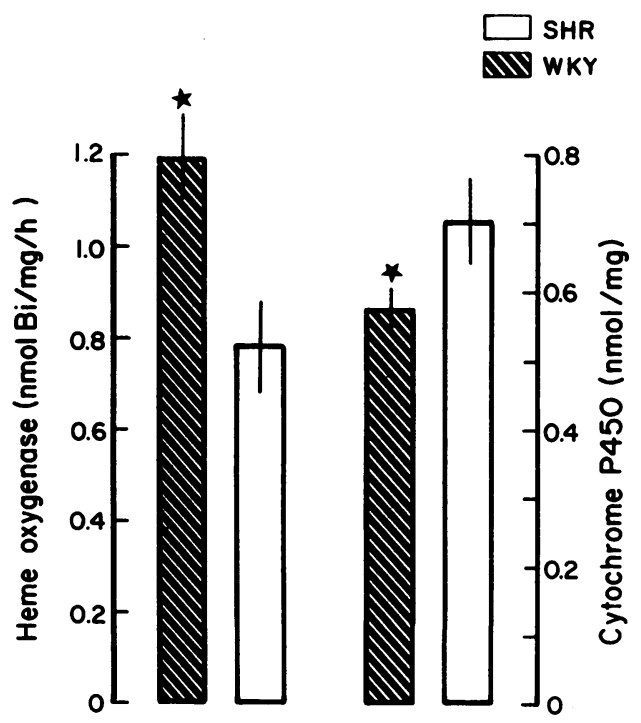

Figure 7. Hepatic heme oxygenase activity and cytochrome $\mathbf{P} 450$ content in SHR and WKY. 7-wk-old SHR $(n=5)$ and WKY $(n=4)$ were killed after overnight fasting; livers were perfused with cold $\mathrm{KCl}$ $(1.15 \% \mathrm{wt} / \mathrm{vol})$, microsomes were prepared and heme oxygenase activity and cytochrome P450 content were measured as described in Methods. Results are means $\pm \mathrm{SD} ;{ }^{*} P<0.025$.

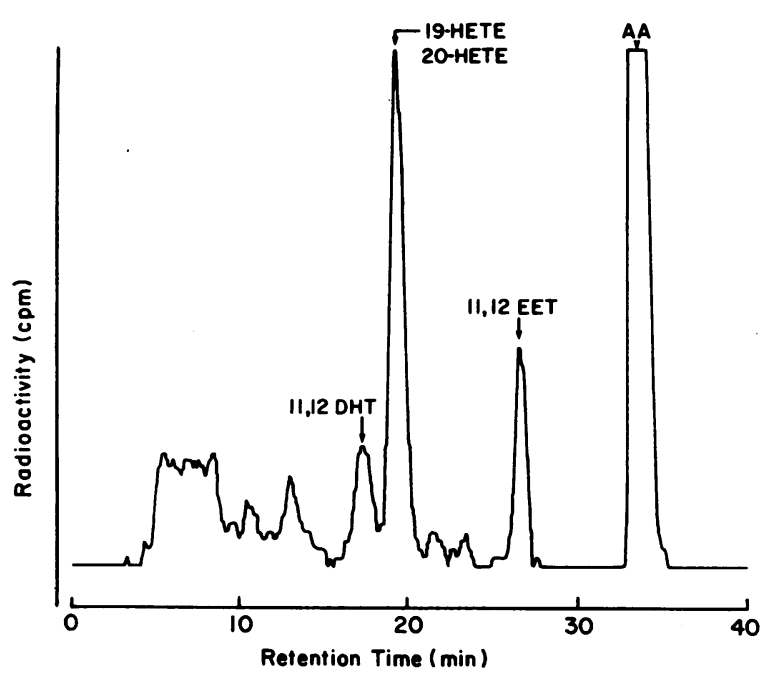

Figure 8. Reverse-phase HPLC separation of renal cytochrome P450dependent AA metabolites in 7-wk-old SHR. Cytochrome P450-related AA metabolism was measured by incubating renal cortical microsomes with $\left[{ }^{14} \mathrm{C}\right] \mathrm{AA}$ and NADPH as described in Methods. Metabolites were extracted and separated by reverse-phase HPLC and their migration was compared to that of known standards.

HETE. Both metabolites exhibit biological activities that promote hypertension, i.e., vasoconstriction and $\mathrm{Na}^{+}-\mathrm{K}^{+}$-ATPase stimulation. The effect of both hemin and heme arginate was dose dependent. At doses of $9 \mathrm{mg} / \mathrm{kg}$ body weight both substances caused inhibition of $\omega / \omega-1$ hydroxylation of $10 \%$ and $12 \%$ for hemin and heme arginate, respectively (data not shown).

\section{Discussion}

Increased levels and activities of the cytochrome P450 system have been documented in liver and kidney of SHR, the animal model for human essential hypertension $(12,13)$. AA is an endogenous substrate of the cytochrome P450 system and the formation of its oxidative metabolites, mainly 19-HETE and

Table II. Cytochrome P450-related AA Metabolism in Kidneys of Control and Treated SHR

\begin{tabular}{|c|c|c|}
\hline & $\omega / \omega-1$ Hydroxylation & Epoxygenation \\
\hline & \multicolumn{2}{|c|}{$\mathrm{nmol} / \mathrm{mg} / 30 \mathrm{~min}$} \\
\hline Control & $3.54 \pm 0.51$ & $2.03 \pm 0.23$ \\
\hline Hemin & $2.31 \pm 0.37^{\ddagger}$ & $1.89 \pm 0.43$ \\
\hline Heme arginate & $2.30 \pm 0.34^{*}$ & $1.65 \pm 0.20$ \\
\hline Heme arginate $+\mathrm{ZnDPBG}$ & $3.25 \pm 0.85^{8}$ & $2.34 \pm 0.53^{8}$ \\
\hline
\end{tabular}

45-d-old SHR were administered heme arginate or hemin $(15 \mathrm{mg} / \mathrm{kg}$ body weight for $4 \mathrm{~d}$ consecutively, i.p.) and heme arginate $(15 \mathrm{mg} / \mathrm{kg}$ body weight for $4 \mathrm{~d}$ consecutively, i.p.) simultaneously with ZnDPBG ( $7 \mathrm{mg} / \mathrm{kg}$ body weight, subcutaneously, $2 \mathrm{~h}$ before each heme arginate administration). Control rats were injected with vehiculum. Renal cortical microsomes $(0.3 \mathrm{mg})$ from control and treated SHR were incubated with $\left[{ }^{14} \mathrm{C}\right] \mathrm{AA}(0.4 \mu \mathrm{Ci})$ and NADPH. Metabolites were extracted and separated by HPLC as described in Methods. Values are the means $\pm \mathrm{SD}, n=5$; significance from control, ${ }^{*} P$ $<0.05,{ }^{\ddagger} P<0.01$; significance from heme arginate group, ${ }^{8} P<0.05$. 
20-HETE, is increased in kidneys of SHR during the period of blood pressure elevation (15). 19-HETE stimulates $\mathrm{Na}^{+}-\mathrm{K}^{+}$ATPase and 20-HETE constricts blood vessels and, therefore, they may contribute to the elevation of blood pressure $(17,18)$. In previous studies we demonstrated that renal cytochrome P450-related AA metabolism in SHR can be depleted by inducing heme oxygenase, which is the rate-limiting enzyme in heme catabolism and thereby affects the availability of heme for hemoproteins such as cytochrome P450 monooxygenase $(28,29)$. Thus, induction of renal heme oxygenase with $\mathrm{SnCl}_{2}$ resulted in a specific decrease in the formation of cytochrome P450-related AA metabolites, 19- and 20-HETE and a reduction of blood pressure in 7-wk-old SHR (16). Although $\mathrm{SnCl}_{2}$ doses used are not associated with acute toxicity in the rat nor a decrease in renal function (16), the doses of $\mathrm{SnCl}_{2}$ which could be used without toxicity in humans are not known. Heme, the substrate of heme oxygenase, is an inducer of its catabolic enzyme and a supressor of enzymes in the heme synthesis pathway, such as $\delta$-aminolevulinic acid synthase, the control and rate-limiting enzyme. As such, it has some therapeutic advantages in treatment of acute hepatic porphyria attacks. However, in order to stabilize hemin and increase its solubility, L-arginine has been added as a ligand to the hemin molecule and heme arginate is now used in Europe for treatment of attacks of AIP.

In the present study, we demonstrated that heme arginate, like $\mathrm{SnCl}_{2}$, targets heme oxygenase, and by modifying its activity, it is possible to alter blood pressure in the SHR. Induction of heme oxygenase by treatment with heme arginate at 15 $\mathrm{mg} / \mathrm{kg}$ per $\mathrm{d}$ selectively prevented the elevation of blood pressure in SHR and the blood pressure-lowering effect of heme arginate could be reversed by inhibition of heme oxygenase. The observed stimulation of heme oxygenase activity was a result of an increased expression of the heme oxygenase gene and mRNA by heme arginate as demonstrated by Northern blot techniques using cDNA of rat hepatic heme oxygenase.

Heme arginate increased hepatic and renal heme oxygenase activity, its mRNA and caused a related change in cytochrome P450 content in all treated groups; adult SHR and WKY of both ages. However, the antihypertensive effect of heme arginate treatment was observed only in SHR. The explanation of these findings could be due to the negative impact on blood pressure of the young SHR caused by depletion of the high level of cytochrome P450. Both kidney and liver of SHR have significantly higher levels of cytochrome P450 content than those in WKY. The reason for this difference can be explained by the level of heme oxygenase activity, one of the important enzymes that regulate heme availability to hemoproteins such as cytochrome P450. Indeed, this is the first report to demonstrate that the basal activity of heme oxygenase is higher in liver of WKY than in that of age-matched SHR. Alternatively, a degradation of sensitive cytochrome P450 isozymes, which are responsible for elevation of blood pressure and are expressed in SHR, but not in WKY, can account for these differences. Indeed, when measuring the effect of heme arginate on P450-related arachidonate metabolism, a specific reduction in the formation of $\omega / \omega-1$ hydroxylated compounds was observed. In that 19-HETE and 20HETE possess biological activities that could contribute to the development of hypertension, a reduction in their formation brought on by heme arginate treatment may be one of the causes for the blood pressure lowering effect of heme arginate.

A similar effect was demonstrated for another inducer of heme oxygenase, $\mathrm{SnCl}_{2}$. However, the effect of heme arginate on blood pressure of SHR is different from that of $\mathrm{SnCl}_{2}$. $\mathrm{SnCl}_{2}$ lowers blood pressure only in young $\mathrm{SHR}$, whereas heme arginate significantly reduced blood pressure in old SHR, although to a much lesser degree. The difference is due to the arginine component of heme arginate. L-arginine, at the dose used, is devoid of any effect on heme oxygenase, but it is the substrate of endothelium-derived relaxing factor (NO) and as such is a potent vasodilator in vitro and in vivo (30). This property may add to the blood pressure lowering effect of hemin itself. In recent experiments, we demonstrated that Larginine lowers blood pressure in vivo in hypertensive rats (manuscript in preparation). Recently, Rees et al. (31) and Aisaka et al. (32) demonstrated that administration of a specific inhibitor of NO formation, $\mathrm{N}^{\mathrm{G}}$-monomethyl-L-arginine, to rabbits or guinea pigs, resulted in a sustained dose-dependent increase in arterial blood pressure, suggesting that NO formation from L-arginine plays a role in the regulation of blood pressure and further substantiating our finding that L-arginine itself may lower blood pressure via NO formation. The heme component of heme arginate shared common properties with $\mathrm{SnCl}_{2}$ inasmuch as it induced renal heme oxygenase, depleted cytochrome P450, reduced the formation of 19- and 20-HETE, and reduced blood pressure.

\section{Acknowledgments}

The authors wish to thank Dr. Ken Omata for his valuable assistance and Mrs. Joyce Eshet for typing the manuscript.

This study was supported in part by grants AM-29742 and EY-06513 from the National Institutes of Health. Dr. Schwartzman is a recipient of the Irma T. Hirschl Career Scientist Award.

\section{References}

1. Bissell, D. M. 1988. Disorders of porphyrins or metals. In Cecil Textbook of Medicine, Volume 1. J. B. Wyngaarden and L. H. Smith, editors. W. B. Saunders Co., Philadelphia. 1182-1187.

2. Tenhunen, R. 1987. Heme arginate: its characterization, metabolism and clinical implications. In New Therapeutic Approach to Hepatic Porphyrias. P. Mustajoki, editor. Vammalan Kirjapaino Oy, Helsinki. 36-43.

3. Mustajoki, P., R. Tenhunen, O. Tokola, and G. Gothoni. 1986. Haem arginate in the treatment of acute hepatic porphyrias. Br. Med. J. 293:538-539.

4. Abraham, N. G., M. L. Friedland, and R. D. Levere. 1983. Heme metabolism in erythroid and hepatic cells. Prog. Hematol. 13:75-130.

5. Kordac, V., and P. Martasek. 1986. Haem arginate in acute hepatic porphyrias. Br. Med. J. 293:1098.

6. Nordmann, Y., J. C. Deybach, J. F. Devars du Marne, and M. Cerf. 1987. Treatment of acute hepatic porphyrias with heme: a comparison of heme arginate and conventional heme therapy. In New Therapeutic Approach to Hepatic Porphyrias. P. Mustajoki, editor. Vammalan Kirjapaino Oy, Helsinki. 56-59.

7. Kordac, V., M. Kozakova, and P. Martasek. 1989. Changes of myocardial functions in acute hepatic porphyrias: role of heme arginate administration. Ann. Med. 21:273-276.

8. Okamoto, K., and K. Aoki. 1963. Development of a strain of spontaneously hypertensive rats. Jpn. Circ. J. 27:282-293.

9. Kawabe, K., T. X. Watanabe, K. Shiono, and H. Sokabe. 1978. Influence of blood pressure of renal isografts between spontaneously hypertensive and normotensive rats, utilizing the F1 hybrids. Jpn. Heart J. 19:886-894.

10. Beierwaltes, W. H., W. J. Arendshorst, and P. J. Klemmer. 1982. Electrolyte and water balance in young spontaneously hypertensive rats. Hypertension. 4:908-915. 
11. Diley, J. R., C. T. Stier, and W. J. Arendshorst. 1984. Abnormalities in glomerular function in rats developing spontaneous hypertension. Am. J. Physiol. 246:F12-F20.

12. Merrick, B. A., M. H. Davis, D. E. Cook, T. L. Holeslaw, and K. Craig Schnell. 1985. Alterations in hepatic microsomal drug metabolism and cytochrome P450 proteins in spontaneously hypertensive rats. Pharmacology (Basel). 30:129-135.

13. Sacerdoti, D., N. G. Abraham, J. McGiff, and M. L. Schwartzman. 1988. Renal cytochrome P450-dependent metabolism of arachidonic acid in spontaneously hypertensive rats. Biochem. Pharmacol. 37:521-527.

14. Kappas, A., and G. S. Drummond. 1986. Control of heme metabolism with synthetic metalloporphyrins. J. Clin. Invest. 77:335339.

15. Simionatto, C. S., K. E. Anderson, G. S. Drummond, and A. Kappas. 1985. Studies on the mechanism of Sn-protoporphyrin suppression of hyperbilirubinemia: inhibition of heme oxidation and bilirubin production. J. Clin. Invest. 75:513-521.

16. Sacerdoti, D., B. Escalante, N. G. Abraham, J. C. McGiff, R. D. Levere, and M. L. Schwartzman. 1989. Treatment with tin prevents the development of hypertension in spontaneously hypertensive rats. Science (Wash. DC). 243:388-390.

17. Escalante, B., J. R. Falck, P. Yadagiri, L. Sun, and M. L. Schwartzman. 1988. 19(s)hydroxyeicosatetraenoic acid is a potent stimulator of renal $\mathrm{Na}^{+}-\mathrm{K}^{+}$-ATPase. Biochem. Biophys. Res. Commun. 152:1269-1273.

18. Escalante, B., W. C. Sessa, J. R. Falck, P. Yadagiri, and M. Laniado Schwartzman. 1989. Vasoactivity of 20-hydroxyeicosatetraenoic acid is dependent on metabolism by cyclooxygenase. J. Pharmacol. Exp. Ther. 248:229-232.

19. Lowry, O. H., N. J. Rosenbrough, A. L. Farr, and R. J. Randall. 1951. Protein measurement with the Folin phenol reagent. J. Biol. Chem. 193:265-275.

20. Omura, T., and R. Sato. 1964. The carbon monoxide-binding pigment of liver microsomes. J. Biol. Chem. 239:2370-2378.

21. Tenhunen, R., H. S. Marver, and R. Schmid. 1970. The enzy- matic catabolism of hemoglobin: stimulation of microsomal heme oxygenase by hemin. J. Lab. Clin. Med. 75:410-421.

22. Abraham, N. G., J. D. Lutton, M. L. Freedman, and R. D. Levere. 1986. Benzene modulation of liver cell structure and hemecytochrome P450 metabolism. Am. J. Med. Sci. 292:81-86.

23. Shibahara, S., R. Muller, H. Taguchi, and T. Yoshida. 1985 Cloning and expression of cDNA for rat heme oxygenase. Proc. Natl. Acad. Sci. USA. 82:7865-7869.

24. Shibahara, S., R. Muller, and H. Taguchi. 1987. Transcriptional control of rat heme oxygenase by heat shock. J. Biol. Chem. 262:12889-12892.

25. Abraham, N. G., J. H-C. Lin, S. M. Mitrione, M. L. Schwartzman, R. D. Levere, and S. Shibahara. 1988. Biochem. Biophys. Res. Commun. 150:717-722.

26. Feinberg, A. P., and B. Vogelstein. 1983. A technique for radiolabeling DNA restriction endonuclease fragments to high specific activity. Anal. Biochem. 132:6-13.

27. Martasek, P., K. Solangi, A. I. Goodman, R. D. Levere, R. J. Chernick, and N. G. Abraham. 1988. Properties of human kidney heme oxygenase: inhibition by synthetic heme analogues and metalloporphyrins. Biochem. Biophys. Res. Commun. 157:480-487.

28. Schwartzman, M. L., N. G. Abraham, M. A. Carroll, R. D. Levere, and J. C. McGiff. 1986. Regulation of arachidonic acid metabolism by cytochrome P450 in rabbit kidney. Biochem. J. 238:283-240.

29. Abraham, N. G., J. H-C. Lin, M. L. Schwartzman, R. D. Levere, and S. Shibahara. 1988. The physiological significance of heme oxygenase. Int. J. Biochem. 20:543-558.

30. Ignarro, L. J. 1989. Endothelium-derived nitric oxide: actions and properties. FASEB (Fed. Am. Soc. Exp. Biol.) J. 3:31-36.

31. Rees, D. D., M. J. Palmer, and S. Moncada. 1989. Role of endothelium-derived nitric oxide in the regulation of blood pressure. Proc. Natl. Acad. Sci. USA. 86:3375-3378.

32. Aisaka, K., S. S. Gross, O. W. Griffith, and R. Levi. 1989. $N^{G}$-methylarginine, an inhibitor of endothelium-derived nitric oxide synthesis, is a potent pressor agent in the guinea pig: does nitric oxide regulate blood pressure in vivo? Biochem. Biophys. Res. Commun. 160:881-886. 